\title{
Colonic taeniasis
}

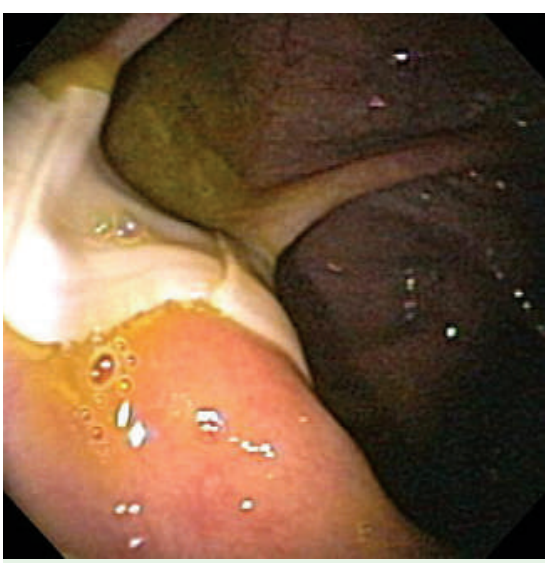

Fig. 1 Flat, white, mobile worm emerging from ileocecal valve.

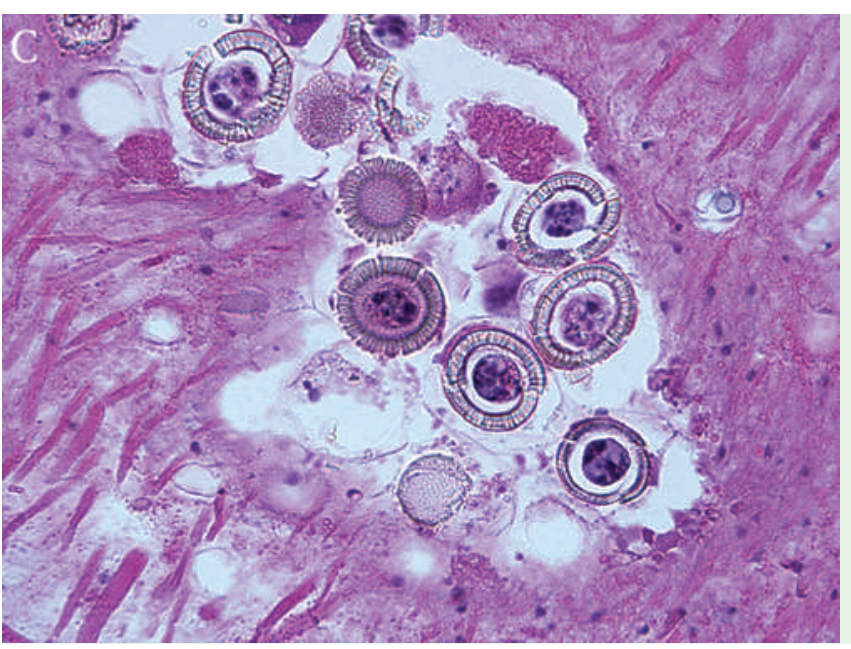

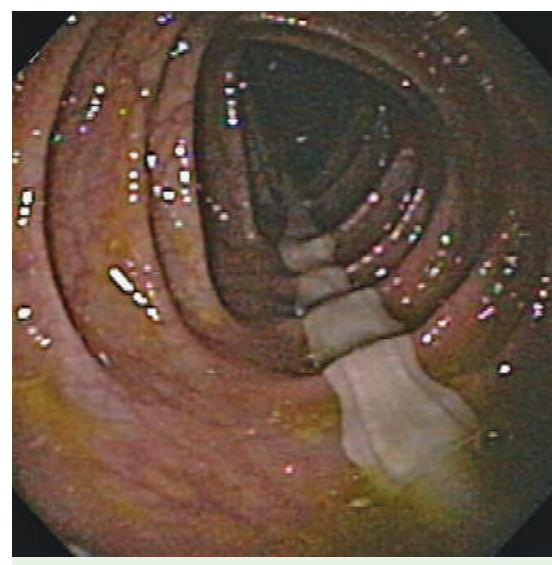

Fig. 2 Extension of worm through transverse colon.
Fig. 3 Taenia spp. eggs. Original magnification $\times 40$.
A 52-year-old Tibetan male was referred for evaluation of rectal bleeding and intermittent mid abdominal pain. He reported frequent loose stools but no associated fever or weight loss. Results from physical exam were within normal limits. Hemoglobin level was $13.1 \mathrm{~g} / \mathrm{dL}$ (normal range $14-18 \mathrm{~g} / \mathrm{dL}$ ), and white-cell count was $5100 / \mathrm{mm}^{3}$ (normal 4800-10800/ $\mathrm{mm}^{3}$ ) with $13 \%$ eosinophils (normal $1 \%-4 \%$ ). Colonoscopy revealed small nonbleeding internal hemorrhoids, and a white ribbon-like structure protruding from the ileocecal valve ( $\bullet$ Fig. 1) and extending throughout the entire colon ( $\bullet$ Fig. 2). A segment of the mobile worm was successfully removed using biopsy forceps, and histologic evaluation demonstrated parasite eggs morphologically consistent with Taenia spp. (๑ Fig. 3, Video 1).
Taenia solium and T. saginata are the most common species of tapeworms infecting humans. Although the worm normally resides in the small intestine it can grow up to $25 \mathrm{~m}$ and extend into the large intestine. The patient was treated successfully with one dose of praziquantel.

Endoscopy_UCTN_Code_CCL_1AD_2AZ

\section{F. Francois, I. Cho}

New York University School of Medicine, New York, USA

\section{Bibliography}

DOI $10.1055 / \mathrm{s}-2007-966965$

Endoscopy 2008; 40: E28

(c) Georg Thieme Verlag KG Stuttgart · New York . ISSN 0013-726X

\section{Corresponding author}

\section{F. Francois, MD}

Division of Gastroenterology (11132N) VA New York Harbor Healthcare System 423 East 23rd Street

New York

NY 10010

USA

Fax: +1-212-951-3481

fritz.francois@med.nyu.edu

\section{Video 1}

Mobile tapeworm moving in colon and grabbed with forceps. 